\title{
Qualidade da informação em saúde: um estudo sobre o vírus do papiloma humano (HPV) em websites brasileiros
}

\author{
Quality of health information: a study of human papillomavirus (HPV) on \\ Brazilian websites
}

\section{Calidad de la información en salud: un estudio sobre el virus del papiloma humano (HPV) en sitios web brasileños}

\author{
Renata Ivone Garcia ${ }^{1, a}$ \\ renataivgarcia@gmail.com | http://orcid.org/0000-0002-1479-4732
}

Márcio Matias ${ }^{1, b}$

matias.m@ufsc.br | https://orcid.org/o000-0002-4728-3592

Lia Caetano Bastos ${ }^{2, b}$

lia@ecv.ufsc.br | https://orcid.org/0000-0002-8822-7634

Rogério Cid Bastos ${ }^{2, b}$

rogerio@inf.ufsc.br | https://orcid.org/o000-0002-3775-1516

Fernanda dos Santos Koehler ${ }^{2, c}$

admfernandadossantos@gmail.com | https://orcid.org/0000-0003-0053-7070

\begin{abstract}
${ }^{1}$ Universidade Federal de Santa Catarina, Programa de Pós-Graduação em Ciência da Informação. Florianópolis, SC. Brasil. 2 Universidade Federal de Santa Catarina, Programa de Pós-Graduação em Engenharia e Gestão do Conhecimento. Florianópolis, SC, Brasil.
\end{abstract}

\footnotetext{
a Especialização em Gestão de Bibliotecas Escolares pela Universidade Federal de Santa Catarina.

${ }^{\text {b }}$ Doutorado em Engenharia de Produção pela Universidade Federal de Santa Catarina.

c Mestrado em Engenharia e Gestão do Conhecimento pela Universidade Federal de Santa Catarina.
}

\section{Resumo}

A internet vem se tornando para a população uma fonte comum de busca de informações sobre temas ligados à saúde, inclusive sobre o vírus do papiloma humano (HPV). Este artigo apresenta uma avaliação da qualidade da informação sobre o tema HPV disponibilizada em websites sobre saúde e um ranking elaborado com base nos resultados obtidos. Para a avaliação foram aplicados 61 indicadores, divididos entre os critérios de conteúdo, usabilidade e legibilidade. No que se refere ao conteúdo, os websites em questão apresentaram informações sobre exames de diagnóstico, prevenção, tratamento e patologias que podem ser desenvolvidas. Quanto à usabilidade, todos os websites avaliados dispõem de um menu principal e possuem um layout agradável. Os indicadores da legibilidade foram atendidos em sua grande maioria, uma vez que todos os submetidos a essa avaliação apresentaram uso de cores, tamanho e formato de fontes aprazíveis. Observou-se um nível expressivo de qualidade das informações sobre o HPV disponibilizadas nos websites avaliados.

Palavras-chave: informação sobre saúde ao consumidor; papillomaviridae; avaliação de websites sobre saúde; qualidade da informação; saúde na internet. 


\begin{abstract}
The internet has become for the population a common source of search for information about issues related to health, including the human papillomavirus (HPV). This article presents an evaluation of the quality of the information about the HPV available on health websites and a ranking based on its results. 61 indicators were used to do the evaluation, divided into content, usability and readability criteria. In regard to content, the websites under evaluation presented information about diagnostic exams, prevention, treatment and the pathologies that can be developed. All those websites have a main menu and a pleasant layout. The indicators of readability, for the most part, were satisfied, since the websites showed attractive use of colors, size and format of fonts. It can be observed a significant level of quality of information about HPV available on the websites evaluated.
\end{abstract}

Keywords: health information to consumer; papillomaviridae; evaluation of health websites; quality of information; health internet.

\title{
Resumen
}

La internet se ha convertido en una fuente común de búsqueda de temas relacionados con la salud, incluso sobre el virus del papiloma humano (HPV). Este artículo presenta una evaluación de la calidad de la información disponible en sitios web sobre el tema del HPV y un ranking elaborado con base en los resultados obtenidos. Para la evaluación se aplicaron 61 indicadores, divididos entre los criterios de contenido, usabilidad y legibilidad. En lo que respecta al contenido, los sitios web presentan información sobre exámenes de diagnóstico, prevención, tratamiento, y sobre las patologías que pueden ser desarrolladas. En lo que concierne a la usabilidad, todos los sitios web evaluados disponen de un menú principal y tienen un diseño gráfico agradable. Los indicadores de legibilidad fueron atendidos en su gran mayoría, en vista de todos los sitios web evaluados hayan presentado uso de colores, tamaño y formato de fuentes agradables. Se observó un nivel expresivo de calidad de la información sobre el HPV disponible en los sitios web evaluados.

Palabras clave: información sobre salud al consumidor; papillomaviridae; evaluación de sitios web sobre salud; calidad de la información; salud en internet. Contribuição dos autores: todos os autores contribuíram significativamente na concepção, desenho do estudo, aquisição,
análise, interpretação dos dados, redação do artigo e revisão crítica do conteúdo.

Declaração de conflito de interesses: não há.

Fontes de financiamento: Capes, CNPq.

Considerações éticas: não há.

Agradecimentos/Contribuições adicionais: não há.

Histórico do artigo: Submetido: 08.ago.2017 | Aceito: 31.jan.2018 | Publicado: 30.mar.2018.

Apresentação anterior: não houve.

Licença CC BY-NC atribuição não comercial. Com essa licença é permitido acessar, baixar (download), copiar, imprimir, compartilhar, reutilizar e distribuir os artigos, desde que para uso não comercial e com a citação da fonte, conferindo os devidos créditos de autoria e menção à Reciis. Nesses casos, nenhuma permissão é necessária por parte dos autores ou dos editores. 


\section{Introdução}

Na sociedade contemporânea, o ambiente virtual tem se caracterizado como um espaço cada vez mais representativo para a disseminação da informação sobre diferentes áreas do conhecimento. A internet possibilita que, além de consumir informação, as pessoas participem de sua produção, surgindo assim um número expressivo de websites. Neste sentido, a internet é a espinha dorsal da comunicação global mediada por computadores, de maneira que a maior parte das redes é ligada por ela ${ }^{1}$.

A internet, caracterizada pelo seu dinamismo, pela quebra de barreira geográfica e linguística, tornouse, para a população, uma fonte comum de busca de informações sobre temas ligados à saúde. No ano de 2009, no Brasil, cerca de 39\% dos internautas já acessavam a internet procurando informações ou serviços relacionados com a saúde². Passados oito anos, a preocupação com a qualidade dessas informações disponibilizadas nos websites de saúde tem recebido cada vez mais atenção, resultando em iniciativas e estudos voltados para a sua avaliação.

Em âmbito internacional, algumas iniciativas para a qualidade das informações sobre saúde podem ser vistas como, por exemplo, os "critérios para avaliar a qualidade da informação sobre saúde na internet”3 estabelecidos pela AHRQ - Agency for Healthcare Research and Quality (Agência de pesquisa e qualidade da assistência médica), ligada ao United States Department of Health \& Human Services (Departamento de Saúde e Serviços Humanos dos Estados Unidos). Ainda nesse país, a Internet Healthcare Coalition (IHC), uma organização sem fins lucrativos, estabeleceu o eHealth Code of Ethics, um código de ética para sites sobre saúde, que "visa garantir que pessoas possam confiar na informação disponível e tenham plena compreensão dos riscos inerentes à adoção desta ou daquela prática" 3 .

Fundada em 1995 e com sede na Suíça, a Fundação Health On the Net (HON) é uma organização não governamental e sem fins lucrativos que visa incentivar a divulgação de informações de saúde de qualidade para pacientes e profissionais assim como para o público em geral através da internet. Essa fundação, por meio da certificação HONCode, atribui um selo de qualidade para os websites de saúde que atendam aos oito princípios estabelecidos no instrumento. Esse selo demonstra que o website publica informações transparentes.

No Brasil, destaca-se o Guia de ética para sites de medicina e saúde na internet ${ }^{i}$ desenvolvido pelo Conselho Regional de Medicina de São Paulo (Cremesp), que estabelece princípios éticos norteadores de uma política de autorregulamentação e critérios de conduta dos websites de saúde e medicina na internet ${ }^{3}$. Por conseguinte, "Médicos e instituições de saúde registrados no Cremesp passaram a ficar obrigados a adotar esse guia para efeito de idealização, registro, criação, manutenção, colaboração e atuação profissional em domínios, sites, páginas, ou portais sobre medicina e saúde na internet”3.

Além do guia supracitado, no Brasil podem-se destacar estudos como a tese intitulada Proposta de critérios de qualidade para avaliação da informação em saúde recuperada nos sites brasileiros da world wide web $^{4}$, que teve como objetivo principal avaliar, com base nos critérios de qualidade descritos na literatura especializada em saúde, a qualidade do conteúdo da informação sobre hipercolesterolemia obtida por meio dos mecanismos de buscas gerais da web. A autora identificou como padrão básico de critérios e indicadores de qualidade, os de credibilidade, de conteúdo e de apresentação da página ${ }^{4}$.

Utilizando os oitos princípios estabelecidos no HONcode, foi desenvolvido um estudo objetivando avaliar a qualidade das informações sobre gagueira em websites brasileiros. Para isso, eles foram selecionados por meio de uma busca do termo 'gagueira' no Google, feita apenas por páginas no Brasil. Foram selecionados cinco websites para se averiguar a natureza e o conteúdo das informações neles encontradas e se avaliar a qualidade destas ${ }^{5}$.

i São Paulo (Estado). Conselho Regional de Medicina do Estado de São Paulo. Guia de ética para sites de medicina e saúde na internet [Internet]. [citado 19 jan 2015] Disponível em: http://www.cremesp.org.br/?siteAcao=Publicacoes\&acao=detalhes capitulos\&cod capitulo=26 apud ${ }^{3}$. 
Outro estudo objetivou avaliar a estrutura, a qualidade da informação e a navegabilidade como material didático de websites sobre 'primeiros socorros'. Para avaliação da qualidade da informação foi estabelecido um instrumento próprio, baseado em alguns modelos já existentes e composto por dois critérios de avaliação: um deles - relacionado à apresentação e ao conteúdo geral - permitiu avaliar se o website era visualmente adequado, de fácil navegação e se mantinha a atenção do usuário; o outro - qualidade das informações em cada capítulo do website - possibilitou avaliar a legibilidade, a clareza e a objetividade de imagens, vídeos e áudios e a adequação do conteúdo ${ }^{6}$.

Diferentemente dos estudos empíricos mencionados, foi desenvolvida no ano de 2015 uma pesquisa com o objetivo de revelar alguns critérios de avaliação da qualidade das informações encontradas em websites de saúde. Como resultado do estudo, os autores agruparam, em três grandes dimensões - técnica, de conteúdo e de design -, oitenta critérios que demonstram qualidade de informação em websites de saúde. Ainda com base na pesquisa, recomendaram a criação de um selo de qualidade para websites de saúde no Brasil3.

A busca de conteúdos sobre saúde na internet tem mudado a relação entre os médicos e seus pacientes, uma vez que estes já chegam munidos de informações em suas consultas. A preocupação maior reside no fato de que muitos dos usuários acabam utilizando as referências que encontram na internet para realizarem seus próprios diagnósticos e encontrarem 'possíveis medicamentos' para solução de seus sintomas.

A preocupação reside também na forma como a internet poderia ser utilizada para alertar a população de doenças epidêmicas que, no passado, já tiveram altos índices e conseguiram o seu controle com esforços da medicina. Para continuarem sob controle, tais doenças, como as causadas pelo vírus do papiloma humano (HPV); pelo vírus da imunodeficiência humana (HIV); a sífilis; e outras têm a internet como um bom canal de disseminação de informações e de comunicação com a população, principalmente, a mais jovem.

Ocorreu em Nova York, entre os dias 25 a 27 de setembro de 2015, uma reunião entre os chefes de Estado e de Governo para definir a "Agenda 2030 para o Desenvolvimento Sustentável", composta por 17 objetivos e 169 metas. De maneira que, entre as metas estabelecidas no "Objetivo 3. Assegurar uma vida saudável e promover o bem-estar para todos, em todas as idades"7, está a meta 3.3 "Até 2030, acabar com as epidemias de Aids, tuberculose, malária e doenças tropicais negligenciadas, e combater a hepatite, doenças transmitidas pela água, e outras doenças transmissíveis" do papiloma humano (HPV).

O HPV é um grupo de vírus extremamente comum em diversos países. Deste grupo, dois tipos de HPV (16 e 18) causam 70\% dos casos de câncer do colo do útero em todo o mundo, sendo que este é o segundo câncer mais comum em mulheres que vivem em regiões menos desenvolvidas. Em 2012, cerca de 27 mil mulheres morreram de câncer do colo do útero, e mais de $85 \%$ dessas mortes ocorreram em países de baixa e média renda. Nos países em desenvolvimento, o acesso limitado ao diagnóstico eficaz significa que a doença muitas vezes não é identificada até que esteja em estágio mais avançado. Além disso, as perspectivas para o tratamento de tal doença em estágio final pode ser limitada, resultando em uma maior taxa de morte por câncer de colo de útero nesses países ${ }^{8}$.

Nesse contexto, este artigo tem como objetivo avaliar a qualidade da informação sobre o tema HPV disponibilizada em websites de saúde e apresenta um ranking elaborado com base nos resultados obtidos. Para os usuários é importante saber quais sites contêm informações com qualidade e, portanto, nos quais se pode confiar. Para aqueles que proveem o conteúdo do site, compreender os quesitos de qualidade esperados em websites de saúde contribui para o aprimoramento e, consequentemente, melhores resultados para quem faz a busca. O HPV foi escolhido como tema de busca por ser um vírus que acomete grande parte da população, mas que, no entanto, ainda pouco se fala abertamente sobre ele, de forma que as pessoas, sempre que sentem necessidade de informações a seu respeito, buscam em websites. 


\section{Métodos de pesquisa}

O estudo tem por abordagem a pesquisa de métodos mistos, ou seja, foram utilizados métodos qualitativos e quantitativos para alcançar os objetivos propostos. Nesse tipo de abordagem, o pesquisador "coleta e analisa de modo persuasivo e rigoroso tanto os dados qualitativos quanto quantitativos (tendo por

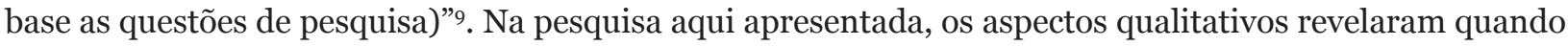
foi analisada, por meio de indicadores, a qualidade da informação a respeito do HPV nos websites sobre saúde. Já no que diz respeito aos métodos quantitativos, ficam evidentes quando foram atribuídos pontos e pesos para cada indicador de avaliação, objetivando a criação de um ranking final sobre a qualidade da informação encontrada nos websites avaliados.

Para definição do corpus da pesquisa foi utilizada como referência uma simulação em que um cidadão leigo na área da saúde realiza uma pesquisa sobre o HPV no mecanismo de busca mais popular no país. Dessa maneira, optou-se por fazer uso de pesquisa pela sigla 'HPV' no motor de busca Google por seu critério de popularidade. Assim, a busca foi realizada no dia 10 de setembro de 2016, e os dez primeiros resultados (primeira página) foram selecionados, tendo em vista que, de maneira geral, o buscador hierarquiza websites mais relevantes para o termo pesquisado e mais citados por outros websites. Identificou-se que dois dos dez resultados apresentados se referiam a um mesmo website; três são de responsabilidade governamental ou de centro de pesquisa ligado a universidades federais, configurando assim referências para os demais; e um resultado remetia à Wikipédia, que é uma enciclopédia livre. Dessa maneira, o corpus da pesquisa foi composto pelos cinco websites dispostos no Quadro 1.

Quadro 1. Lista de websites sobre saúde que compõe o corpus da pesquisa

\begin{tabular}{|l|l|}
\hline \multicolumn{1}{|c|}{ Nome do website } & \multicolumn{1}{c|}{ Link do website } \\
\hline Gineco & www.gineco.com.br/ \\
\hline Minha Vida & www.minhavida.com.br \\
\hline Tua saúde & $\underline{\text { www.tuasaude.com }}$ \\
\hline Oncoguia & $\underline{\text { www.oncoguia.org.br }}$ \\
\hline Mulher consciente & $\underline{\text { www.mulherconsciente.com.br }}$ \\
\hline
\end{tabular}

Fonte: Os autores (2018).

Para a avaliação da qualidade das informações dos websites sobre saúde relacionadas ao vírus do HPV, utilizou-se uma adaptação do instrumento de avaliação desenvolvido no trabalho intitulado Avaliação de sites de saúde em questão: a aids nos sites brasileiros de organizações não governamentais (ONG) de lésbicas, gays, bissexuais, travestis e transexuais (LGBT) ${ }^{10}$. 
No Quadro 2 podem ser visualizados os três critérios propostos no instrumento, bem como alguns indicadores relacionados a cada um dos critérios.

Quadro 2. Critérios adotados na pesquisa

\begin{tabular}{|l|l|}
\hline \multicolumn{1}{|c|}{ Critério } & \multicolumn{1}{c|}{ Indicadores relacionados } \\
\hline Conteúdo & $\begin{array}{l}\text { Autoria; responsabilidade do site; fonte da informação; data da atualização da informação; } \\
\text { acurácia e a cobertura da informação relacionando o diagnóstico, a prevenção, o tratamento e } \\
\text { consequências. }\end{array}$ \\
\hline Usabilidade & $\begin{array}{l}\text { Capacidade que tem um determinado website de permitir que o usuário circule com facilidade } \\
\text { e rapidez em seu interior e nos links que disponibiliza; as imagens, diagramas e fotografias } \\
\text { sobre a doença devem ter a referência de sua fonte, ter qualidade visual e ajudar a esclarecer } \\
\text { a informação oferecida, mantendo com o texto uma relação complementar; é fundamental que } \\
\text { existam os mecanismos de busca; endereço e telefone da entidade que mantém o website. }\end{array}$ \\
\hline Legibilidade & $\begin{array}{l}\text { Grau de compreensão do que está escrito por parte do usuário; a informação apresentada de } \\
\text { forma agradável e rápida; informações de forma compreensível para leigos. }\end{array}$ \\
\hline
\end{tabular}

Fonte: Adaptado de Pereira, Santos, Cruz e Torres $(2013)^{10}$.

Os indicadores de cada critério são apresentados em forma de questões e compõem um checklist. As respostas apresentam valores que variam entre zero e 10 (dez) pontos, e um peso é atribuído de acordo com o grau de importância daquela questão para o critério analisado, sendo tanto a pontuação das respostas quanto o grau de importância estabelecidos por Pereira, Santos, Cruz e Torres ${ }^{10}$ com base nos destaques que encontraram na base bibliográfica que pesquisaram. Sobre a pontuação atribuída (10, 5 e o pontos) para cada item, os autores dizem que "foi arbitrada de modo a fazer com que os três indicadores recebessem a mesma pontuação máxima" ${ }^{10}$. Além disso, defenderam a concepção de que as informações em websites de saúde devam abranger aspectos relacionados aos três indicadores de maneira igualitária; dessa forma, o valor da resposta é multiplicado pelo peso atribuído resultando no valor daquele indicador. Além do grau de importância da questão para o critério analisado, os pesos atribuídos "[...] têm a finalidade de fazer com que os três critérios, apesar de terem um número diferente de indicadores possam alcançar ao final a mesma pontuação máxima"10. Neste sentido, somados os resultados atribuídos a cada indicador, será possível verificar a pontuação de cada critério e fazer a análise a partir deste.

No modelo de avaliação apresentado por Pereira, Santos, Cruz e Torres ${ }^{10}$, o critério ‘conteúdo’ é composto por vinte indicadores que somam 300 pontos máximos; o critério 'usabilidade’ também é composto por vinte indicadores que somados resultam em 300 pontos máximos; por fim, o critério 'legibilidade’ é composto por vinte e três indicadores que somados resultam em 300 pontos máximos. Esta distribuição de pesos que proporcionam a mesma soma máxima de pontos nos critérios é importante, conforme afirmam os autores ${ }^{10}$ por permitir uma igualdade de importância dos critérios.

O critério conteúdo aborda a "maneira com que a informação e sua fonte são apresentadas"10; dessa forma, o website precisará, entre outros aspectos, "apresentar o nome e demais dados de seu proprietário e do responsável pelas informações disponibilizadas assim como suas referências”" ${ }^{\prime 0}$. 
No Quadro 3 é possível visualizar o conjunto de indicadores e seus respectivos pesos que compõem o critério de avaliação conteúdo.

Quadro 3. Indicadores de avaliação de conteúdo de website sobre saúde

\begin{tabular}{|c|c|c|c|c|c|}
\hline \multirow{2}{*}{ Indicador } & \multicolumn{3}{|c|}{ Pontos possíveis } & \multirow{2}{*}{ Peso } & \multirow{2}{*}{ Total } \\
\hline & 10 pts & 5 pts & Zero & & \\
\hline Consta o responsável pelo site/ONG? & Sim & & Não & 3 & 30 \\
\hline Constam as credenciais do responsável? & Sim & Em parte & Não & 3 & 30 \\
\hline Consta o patrocinador/parceiro do site? & Sim & & Não & 3 & 30 \\
\hline Consta a data da criação do site? & Sim & & Não & 2 & 20 \\
\hline Consta a data da última atualização? & Sim & & Não & 2 & 20 \\
\hline Quando foi feita última atualização? Há... & 30 dias & 60 dias & 90 dias & 2 & 20 \\
\hline Consta o público a que o website se dirige? & Sim & & Não & 1 & 10 \\
\hline Consta fonte de Informação na página da doença? & Sim & & Não & 2 & 20 \\
\hline Que tipo de fonte de informação foi utilizada? & Experto & Livro & Pessoa & 2 & 20 \\
\hline Consta como fazer o exame diagnóstico da doença? & Sim & Em parte & Não & 1 & 10 \\
\hline Os exames diagnósticos estão de acordo com a ciência? & Sim & Em parte & Não & 1 & 10 \\
\hline Consta como se prevenir da doença? & Sim & Em parte & Não & 1 & 10 \\
\hline A prevenção está de acordo com a ciência? & Sim & Em parte & Não & 1 & 10 \\
\hline O tratamento é preconizado? & Sim & Em parte & Não & 1 & 10 \\
\hline O tratamento está de acordo com a ciência? & Sim & Em parte & Não & 1 & 10 \\
\hline Constam as patologias que podem ser desenvolvidas? & Sim & Em parte & Não & 1 & 10 \\
\hline $\begin{array}{l}\text { As patologias que podem ser desenvolvidas estão de } \\
\text { acordo com a ciência? }\end{array}$ & Sim & Em parte & Não & 1 & 10 \\
\hline Constam anúncios? & Não & Até 5 & + de 5 & 1 & 10 \\
\hline Consta quando o médico deve ser chamado? & Sim & & Não & 1 & 10 \\
\hline Total & & & & & 300 \\
\hline
\end{tabular}

Fonte: Adaptado de Pereira, Santos, Cruz e Torres (2013)

Sobre os indicadores de avaliação de conteúdo de website sobre saúde, apresentados no Quadro 3, é imprescindível indicar que houve uma adaptação do instrumento original ${ }^{10}$. Durante a pesquisa notouse uma inconsistência no peso atribuído ao indicador 'Quando foi feita última atualização? Há...', sendo originalmente peso 1. No entanto, tal indicador versa sobre aspectos relacionados à atualização, item relevante para a qualidade da informação na área de saúde ${ }^{10}$, e que assim estaria junto aos outros indicadores relacionados à atualização e que possuem peso 2.

Realizada a substituição dos pesos do indicador supracitado, percebeu-se a necessidade de ajustar o restante dos indicadores para que somados resultassem em 300 pontos, pois a proposta metodológica de avaliação da qualidade da informação em websites de saúde apresentada "sugere que nenhum dos critérios deva ter mais importância que o outro" ${ }^{10}$. Dessa maneira, os indicadores ‘Constam anúncios?' e ‘Constam anúncios de medicamentos?' foram condensados num único indicador.

Além dessas adaptações, entendeu-se que os indicadores 'Constam as consequências do tratamento?' e 'As consequências estão de acordo com a ciência?' não atendem às informações ligadas ao HPV, pois este pode se manifestar por meio do desenvolvimento de distintas patologias, de maneira que algumas não apresentam consequências do tratamento. Assim, julgou-se oportuno substituir tais indicadores por 
'Constam as patologias que podem ser desenvolvidas?' e 'As patologias que podem ser desenvolvidas estão de acordo com a ciência?', respectivamente.

Para se avaliar a usabilidade, são analisados os aspectos visuais e a ergonomia do website. A usabilidade é a "medida em que um sistema, produto ou serviço pode ser usado por usuários específicos para atingir metas especificadas como eficácia, eficiência e satisfação em um contexto de uso especificado" ${ }^{11}$. Neste sentido, percebe-se que "usabilidade é um atributo de qualidade relacionado à facilidade de uso de algo"12.

A metodologia adotada no estudo mencionado ${ }^{10}$ almeja mensurar a capacidade que tem um website de proporcionar facilidade de navegação para seus usuários considerando os seus conteúdos e os links que disponibiliza. Além de permitir avaliar se a informação é facilmente encontrada dentro do website, a usabilidade busca qualidade nos recursos auxiliares ao conteúdo textual. Dessa maneira "as imagens, diagramas e fotografias sobre a doença devem ter a referência de sua fonte, ter qualidade visual e ajudar a esclarecer a informação oferecida, mantendo com o texto uma relação complementar"10.

O conjunto de indicadores e seus respectivos pesos que compõem o critério de avaliação da usabilidade pode ser visualizado no Quadro 4.

Quadro 4. Indicadores de avaliação da usabilidade de website de saúde

\begin{tabular}{|c|c|c|c|c|c|}
\hline \multirow[b]{2}{*}{ Indicador } & \multicolumn{3}{|c|}{ Pontos possíveis } & \multirow[b]{2}{*}{ Peso } & \multirow[b]{2}{*}{ Total } \\
\hline & 10 pts & 5 pts & Zero & & \\
\hline Existe um menu principal? & Sim & & Não & 3 & 30 \\
\hline O layout geral do website é agradável*? & Sim & + ou - & Não & 3 & 30 \\
\hline É rápido passar de uma página para outra? & Sim & Às vezes & Não & 3 & 30 \\
\hline $\begin{array}{l}\text { Existem links externos que complementam o texto que trata da } \\
\text { doença? }\end{array}$ & Sim & & Não & 2 & 20 \\
\hline Existe um fale conosco? & Sim & & Não & 2 & 20 \\
\hline $\begin{array}{l}\text { Existem meios de comunicação entre os frequentadores do } \\
\text { website (Facebook/Twitter)? }\end{array}$ & Sim & & Não & 2 & 20 \\
\hline Existem imagens na página que trata da doença? & Sim & & Não & 2 & 20 \\
\hline Existem estatísticas de acesso ao site? & Sim & & Não & 2 & 20 \\
\hline Existem menus secundários? & Sim & & Não & 1 & 10 \\
\hline Existe um mapa do site? & $\operatorname{Sim}$ & & Não & 1 & 10 \\
\hline Existem mecanismos de busca interna no site? & Sim & & Não & 1 & 10 \\
\hline Estes mecanismos são ágeis? & Sim & Às vezes & Não & 1 & 10 \\
\hline Estes mecanismos ajudam na busca? & Sim & Às vezes & Não & 1 & 10 \\
\hline Os links externos complementam o texto principal sobre a doença? & $\operatorname{Sim}$ & Às vezes & Não & 1 & 10 \\
\hline Estes links externos são acessíveis facilmente? & Sim & Às vezes & Não & 1 & 10 \\
\hline Estes links externos são agradáveis? & Sim & Às vezes & Não & 1 & 10 \\
\hline $\begin{array}{l}\text { É disponibilizado o endereço e telefone da entidade que mantém } \\
\text { o site? }\end{array}$ & Sim & & Não & 1 & 10 \\
\hline As imagens que tratam da doença têm qualidade visual? & $\operatorname{Sim}$ & Às vezes & Não & 1 & 10 \\
\hline Estas imagens complementam o texto escrito? & Sim & Às vezes & Não & 1 & 10 \\
\hline Total & & & & & 300 \\
\hline
\end{tabular}

Fonte: Adaptado de Pereira, Santos, Cruz e Torres (2013) ${ }^{10}$.

*Nota: Um layout agradável é composto por um equilíbrio na distribuição dos elementos no espaço disponível, objetividade e organização das informações expostas, além de dar atenção para as cores, contrastes, tipos e tamanhos de fontes utilizadas na composição ${ }^{13}$. 
Os indicadores relacionados à legibilidade mensuram o nível de compreensão do texto por parte dos usuários. Ou seja, se estes entendem o que está escrito no website e se há dificuldades no reconhecimento de palavras ou frases nos textos que versam sobre a patologia estudada. A legibilidade "diz respeito às características que possam dificultar ou facilitar a leitura das informações textuais" ${ }^{14}$.

No Quadro 5 é possível visualizar o conjunto de indicadores e seus respectivos pesos que compõem o critério de avaliação da legibilidade.

Quadro 5. Indicadores de avaliação da legibilidade de website sobre saúde

\begin{tabular}{|c|c|c|c|c|c|}
\hline \multirow{2}{*}{ Indicador } & \multicolumn{3}{|c|}{ Pontos possíveis } & \multirow{2}{*}{ Peso } & \multirow{2}{*}{ Total } \\
\hline & 10 pts & 5 pts & Zero & & \\
\hline Qual foi a sua primeira impressão geral do site? & Gostei & + ou - & Não gostei & 2 & 20 \\
\hline Você achou as frases muito longas e difíceis na $1^{\text {a }}$ página? & Não & Um pouco & Sim & 2 & 20 \\
\hline Quantas frases você não entendeu direito na $1^{\mathrm{a}}$ página? & $\begin{array}{l}\text { Uma ou } \\
\text { duas }\end{array}$ & Entre 3 e 5 & 6 ou mais & 2 & 20 \\
\hline $\begin{array}{l}\text { Você encontrou muitas palavras que não conhecia na } 1^{a} \\
\text { página? }\end{array}$ & Não & Um pouco & $\operatorname{Sim}$ & 2 & 20 \\
\hline Quantas palavras você não entendeu direito na $1^{a}$ página? & $\begin{array}{l}\text { Uma ou } \\
\text { duas }\end{array}$ & Entre 3 e 5 & 6 ou mais & 2 & 20 \\
\hline $\begin{array}{l}\text { Assim que você abriu o website encontrou as informações } \\
\text { que procurava sobre a doença? }\end{array}$ & Sim & + ou - & Não & 2 & 20 \\
\hline $\begin{array}{l}\text { Você achou as frases muito longas no texto que aborda o } \\
\text { diagnóstico da doença? }\end{array}$ & Não & Um pouco & Sim & 1 & 10 \\
\hline $\begin{array}{l}\text { Quantas frases sobre o diagnóstico da doença você não } \\
\text { entendeu direito? }\end{array}$ & $\begin{array}{l}\text { Uma ou } \\
\text { duas }\end{array}$ & Entre 3 e 5 & 6 ou mais & 1 & 10 \\
\hline $\begin{array}{l}\text { Você encontrou muitas palavras que não conhecia no } \\
\text { texto que aborda o diagnóstico da doença? }\end{array}$ & Não & Um pouco & Sim & 1 & 10 \\
\hline $\begin{array}{l}\text { Quantas palavras sobre o diagnóstico da doença você não } \\
\text { entendeu direito? }\end{array}$ & $\begin{array}{l}\text { Uma ou } \\
\text { duas }\end{array}$ & Entre 3 e 5 & 6 ou mais & 1 & 10 \\
\hline $\begin{array}{l}\text { Você achou as frases muito longas no texto que aborda a } \\
\text { prevenção da doença? }\end{array}$ & Não & Um pouco & Sim & 1 & 10 \\
\hline $\begin{array}{l}\text { Quantas frases sobre a prevenção da doença você não } \\
\text { entendeu direito? }\end{array}$ & $\begin{array}{l}\text { Uma ou } \\
\text { duas }\end{array}$ & Entre 3 e 5 & 6 ou mais & 1 & 10 \\
\hline $\begin{array}{l}\text { Você encontrou muitas palavras que não conhecia no } \\
\text { texto que aborda a prevenção da doença? }\end{array}$ & Não & Um pouco & Sim & 1 & 10 \\
\hline $\begin{array}{l}\text { Quantas palavras você não entendeu direito no texto que } \\
\text { aborda a prevenção da doença? }\end{array}$ & $\begin{array}{l}\text { Uma ou } \\
\text { duas }\end{array}$ & Entre 3 e 5 & 6 ou mais & 1 & 10 \\
\hline $\begin{array}{l}\text { Você achou as frases muito longas no texto que aborda o } \\
\text { tratamento da doença? }\end{array}$ & Não & Às vezes & $\operatorname{sim}$ & 1 & 10 \\
\hline $\begin{array}{l}\text { Quantas frases sobre o tratamento da doença você não } \\
\text { entendeu direito? }\end{array}$ & $\begin{array}{l}\text { Uma ou } \\
\text { duas }\end{array}$ & Entre 3 e 5 & 6 ou mais & 1 & 10 \\
\hline $\begin{array}{l}\text { Você encontrou muitas palavras que não conhecia no } \\
\text { texto que aborda o tratamento da doença? }\end{array}$ & Não & Às vezes & Sim & 1 & 10 \\
\hline $\begin{array}{l}\text { Quantas palavras sobre o tratamento da doença você não } \\
\text { entendeu direito? }\end{array}$ & $\begin{array}{l}\text { Uma ou } \\
\text { duas }\end{array}$ & Entre 3 e 5 & 6 ou mais & 1 & 10 \\
\hline $\begin{array}{l}\text { Você achou as frases muito longas no texto que aborda as } \\
\text { patologias que podem ser desenvolvidas? }\end{array}$ & Não & Às vezes & Sim & 1 & 10 \\
\hline
\end{tabular}




\begin{tabular}{|c|c|c|c|c|c|}
\hline \multirow{2}{*}{ Indicador } & \multicolumn{3}{|c|}{ Pontos possíveis } & \multirow{2}{*}{ Peso } & \multirow{2}{*}{ Total } \\
\hline & 10 pts & 5 pts & Zero & & \\
\hline $\begin{array}{l}\text { Quantas frases sobre as patologias que podem ser } \\
\text { desenvolvidas você não entendeu direito? }\end{array}$ & $\begin{array}{l}\text { Uma ou } \\
\text { duas }\end{array}$ & Entre 3 e 5 & 6 ou mais & 1 & 10 \\
\hline $\begin{array}{l}\text { Você encontrou muitas palavras que não conhecia } \\
\text { no texto que aborda as patologias que podem ser } \\
\text { desenvolvidas? }\end{array}$ & Não & Às vezes & Sim & 1 & 10 \\
\hline $\begin{array}{l}\text { Quantas palavras sobre as patologias que podem ser } \\
\text { desenvolvidas você não entendeu direito? }\end{array}$ & $\begin{array}{l}\text { Uma ou } \\
\text { duas }\end{array}$ & Entre 3 e 5 & 6 ou mais & 1 & 10 \\
\hline Você recomendará este website a um amigo? & Sim & Talvez & Não & 2 & 20 \\
\hline Total & & & & & 300 \\
\hline
\end{tabular}

Fonte: Adaptado de Pereira, Santos, Cruz e Torres (2013) ${ }^{10}$.

Cabe destacar que, no Quadro 5, foram substituídos quatro indicadores, tendo em vista as adaptações realizadas nos que são relacionados ao critério conteúdo. Dessa maneira, os indicadores que têm relação com as consequências do tratamento previstas no instrumento original ${ }^{10}$, foram substituídos por indicadores que versam sobre as patologias que podem ser desenvolvidas pelo HPV.

A avaliação da qualidade das informações sobre o HPV, por meio da aplicação de três grandes critérios e dos 61 indicadores de qualidade supracitados, foi realizada, em sua grande maioria, pelos pesquisadores, assumindo o papel de especialistas em qualidade da informação. No entanto, aspectos dos websites relacionados a quatro indicadores foram avaliados por um especialista da área de saúde, a saber: os exames diagnósticos estão de acordo com a ciência; a prevenção está de acordo com a ciência; o tratamento está de acordo com a ciência e as consequências estão de acordo com a ciência.

Apresentados os aspectos metodológicos, na próxima seção serão demonstrados os resultados e as discussões da avaliação da qualidade das informações sobre o HPV disponibilizadas em websites brasileiros que abordam aspectos relacionados à saúde.

\section{Apresentação e análise dos resultados}

Relacionado ao critério conteúdo, o website sobre saúde que atendeu a um maior número de indicadores de qualidade foi o 'Tua saúde' com 275 pontos, seguido pelo 'Minha vida' e 'Gineco', com 260 e 255 pontos respectivamente. Em quarto lugar ficou o website 'Oncoguia' com 200 pontos, e logo após o 'Mulher consciente' com 140 pontos. 
No Gráfico 1 é possível visualizar os resultados relacionados ao critério conteúdo aplicado a cada website avaliado.

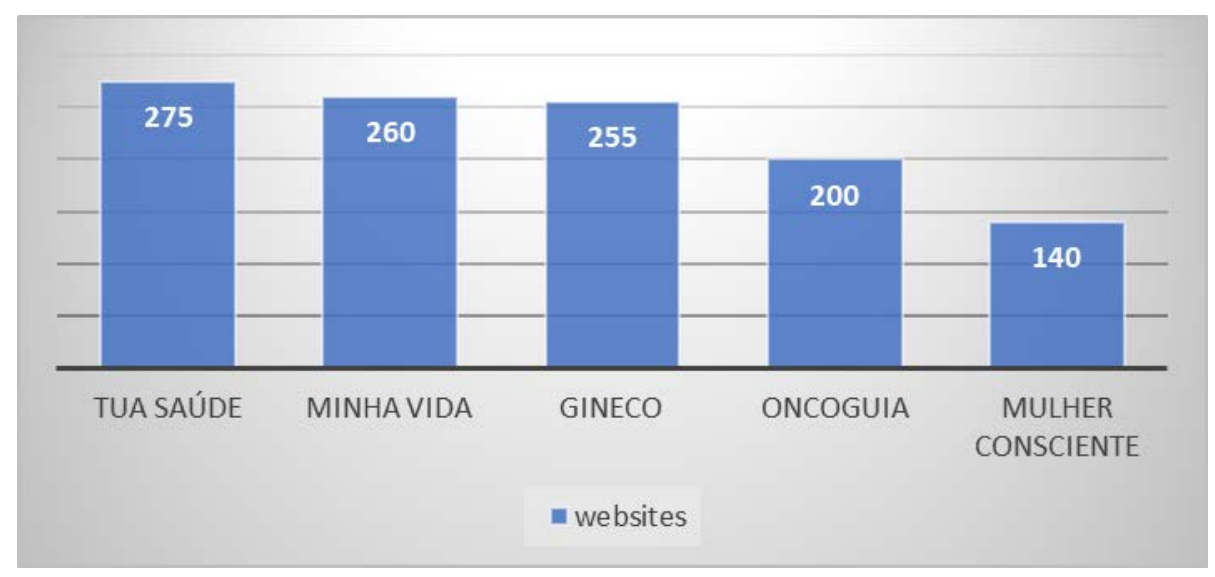

Gráfico 1. Resultados dos indicadores de qualidade com base no critério conteúdo Fonte: Os autores (2018).

De maneira geral, os websites avaliados apresentaram resultados expressivos relacionados à qualidade do conteúdo, destacando-se positivamente os websites 'Gineco', 'Minha vida' e 'Tua saúde'. Estes apresentaram informações sobre o HPV relacionadas aos exames de diagnóstico, à prevenção, ao tratamento e às patologias que podem ser desenvolvidas. Ademais, cabe evidenciar que todos os websites avaliados apresentaram informações sobre prevenção e patologias que podem ser desenvolvidas por meio do vírus HPV.

O website 'Mulher consciente' foi o único que não atendeu a um número considerável de indicadores, tais como: as credenciais do responsável pelo website; data de sua criação, bem como da última atualização; o público ao qual ele se destina, e informações relacionadas ao exame de diagnóstico. Deve ser destacado que as informações sobre o HPV disponibilizadas por esse website encontram-se direcionadas para a patologia câncer de colo de útero, apresentando dessa maneira poucas informações específicas sobre o vírus HPV propriamente dito.

Indicadores relacionados à atualização representam aspecto relevante para a qualidade da informação na área da saúde. No entanto, dos websites avaliados somente o 'Tua saúde', na época da pesquisa, havia atualizado suas informações nos últimos 30 dias. Assim como a atualização, apresentar as fontes de informação consultadas é relevante para a credibilidade e a qualidade das informações em websites sobre saúde; no entanto, o 'Oncoguia' não disponibiliza as fontes de informação utilizadas. Além disso, nele é informado que existem tratamentos para as lesões causadas pelo vírus HPV, porém não os especifica.

No que diz respeito ao critério usabilidade, o website sobre saúde que atendeu ao maior número de indicadores de qualidade foi o 'Tua saúde' com 270 pontos, seguido pelo 'Minha vida' e 'Gineco', com 240 e 220 pontos respectivamente. Em quarto lugar ficou o 'Oncoguia' com 200 pontos, e logo após o 'Mulher consciente' com 170 pontos. 
No Gráfico 2, é possível visualizar os resultados relacionados ao critério usabilidade aplicado a cada website avaliado.

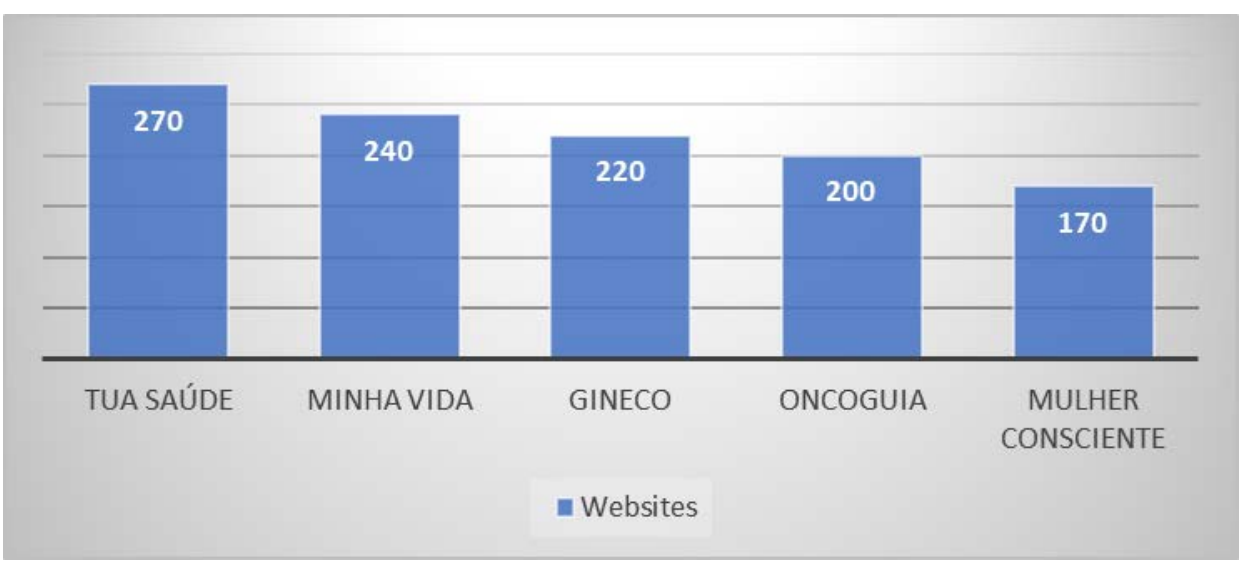

Gráfico 2. Resultados dos indicadores de qualidade com base no critério usabilidade Fonte: Os autores (2018).

Os indicadores referentes ao critério usabilidade foram atendidos de maneira razoável pelos os websites avaliados. Um aspecto pertinente dos dados da avaliação é que todos eles atenderam integralmente aos três indicadores que possuem maior peso, ou seja, todos dispõem de um menu principal, de um layout geral agradável e, internamente, permitem que se passe rapidamente de uma página para outra.

Além dos supracitados, os websites também atenderam por unanimidade os seguintes indicadores: existem meios de comunicação entre os seus frequentadores (Facebook/Twitter); disponibilizam menus secundários e possuem mecanismos de busca interna. Um aspecto relevante relacionado aos mecanismos de busca interna está no website 'Mulher consciente', pois este dispõe de um ícone para a busca, diferentemente dos demais avaliados que disponibilizam uma caixa para a inserção da pesquisa desejada. Além disso, quando o usuário aciona o ícone de busca não é aberta a caixa para inserção do termo desejado; assim, o 'Mulher consciente' não atendeu aos indicadores sobre a agilidade do mecanismo de busca interna, bem como à eficácia dos resultados recuperados.

Referente ao critério legibilidade, o website sobre saúde que atendeu ao maior número de indicadores de qualidade foi o 'Minha vida' com 300 pontos, seguido pela 'Tua vida' com 280 pontos. Em terceiro e quarto lugares ficaram 'Gineco' e 'Oncoguia' com 240 pontos cada. Por último ficou o 'Mulher consciente' com 200 pontos. No Gráfico 3, é possível visualizar os resultados relacionados ao critério legibilidade aplicado para cada website avaliado.

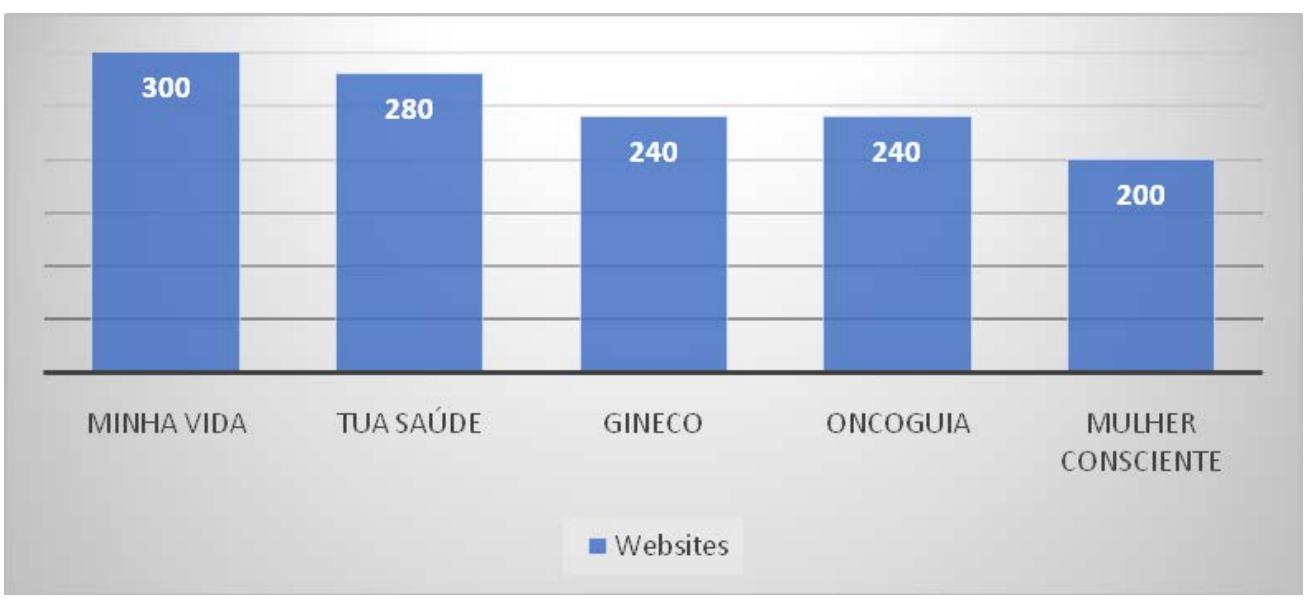

Gráfico 3. Resultados dos indicadores de qualidade com base no critério legibilidade Fonte: Os autores (2018). 
Os indicadores referentes ao critério legibilidade foram atendidos em sua grande maioria pelos websites avaliados, e cabe destacar que todos eles deram uma boa impressão, apresentando o uso de cores, o tamanho e o formato de fontes assim como a disposição das informações aprazíveis. Além disso, as frases foram formadas de maneira curta e inteligível.

Diferentemente dos indicadores ligados às frases, foram identificados na primeira página do website 'Gineco' diversas palavras e termos específicos da área de saúde, facilmente compreensíveis para profissionais ligados à área médica. Nesse website foram identificados mais de seis termos e palavras desse gênero como, por exemplo, 'papilomatose', 'prurido', 'glande' e 'neoplasias'. Assim como ocorreu na primeira página do website 'Gineco', foram observadas diferentes palavras e expressões próprias para profissionais ligados à área de saúde no texto que trata do diagnóstico da doença como, por exemplo, 'condiloma acuminado', 'erupção vesiculosa com base eritematosa', 'umbilicação', 'hipertróficas' e 'pedunculados'.

Atenta-se para o fato de que os websites avaliados são portais que trazem informações sobre a saúde de uma maneira mais ampliada, ou seja, não tratam exclusivamente do vírus HPV. No entanto, entende-se que a organização do website deva favorecer a recuperação de qualquer informação dentro de suas páginas, e isso não ocorreu em 'Tua saúde' e 'Oncoguia'. O indicador relacionado à identificação da informação almejada logo no primeiro acesso ao website não foi contemplado por esses últimos, pois as informações sobre o vírus HPV não estavam na sua primeira página, sendo necessário utilizar outros links para visualizar o conteúdo referente a ele.

Fazendo uso dos dados coletados durante a análise e apresentados durante a pesquisa, pode-se definir um ranking dos websites avaliados de acordo com a qualidade da informação fornecida por cada um. No Quadro 6, é possível visualizar a classificação final, baseada na soma dos três critérios de qualidade de informação estabelecidos: conteúdo, usabilidade e legibilidade.

Quadro 6. Ranking dos websites avaliados de acordo com a qualidade de informação

\begin{tabular}{|c|c|c|c|c|c|}
\hline & \multirow[t]{2}{*}{ Website } & \multicolumn{3}{|c|}{ Critérios } & \multirow{2}{*}{ Total } \\
\hline & & Conteúdo & Usabilidade & Legibilidade & \\
\hline 10 & Tua saúde (www.tuasaude.com) & 275 & 270 & 280 & 825 \\
\hline 20 & Minha vida (www.minhavida.com.br) & 260 & 240 & 300 & 800 \\
\hline 30 & Gineco (www.gineco.com.br/) & 255 & 220 & 240 & 715 \\
\hline 40 & Oncoguia (www.oncoguia.org.br) & 200 & 200 & 240 & 640 \\
\hline 50 & Mulher consciente (www.mulherconsciente.com.br) & 140 & 170 & 200 & 510 \\
\hline
\end{tabular}

Fonte: Os autores (2018).

Os websites 'Tua saúde' e 'Minha vida' se destacaram no atendimento aos critérios e indicadores de qualidade de informação estabelecidos, de maneira que obtiveram o primeiro e segundo lugar, com 825 e 800 pontos respectivamente. Em terceiro lugar, ficou o 'Gineco' com um total de 715 pontos, seguido pelo 'Oncoguia', que obteve 640 pontos, ocupando assim a quarta posição. Por último, assumindo a quinta colocação, encontra-se o website 'Mulher consciente' com 510 pontos.

\section{Considerações finais}

"O paciente chega em um consultório médico e, antes de o especialista falar, ele já começa a dizer todos os sintomas, apontar as soluções para a doença e, por vezes, ainda debater com o doutor, utilizando o argumento "pesquisei na internet e acho que é o caso de tomar outro remédio"'15, fato trazido pelo autor Almeida Jr. no jornal Correio Brasiliense em 2011. Ainda conforme esse autor, no ano de publicação de seu artigo, uma pesquisa realizada pelo instituto Ipsos MORI apontava que $86 \%$ dos brasileiros buscavam 
orientações sobre saúde em sites da internet ${ }^{15}$. Se os números de busca impressionavam em 2011, deduz-se que com a facilidade de acessos esse número seja atualmente muito maior, reforçando a necessidade de se verificar de forma constante a qualidade das informações ofertadas por websites de informações sobre saúde que são tomadas como verdades por diferentes leitores.

Diante disso, este artigo apresenta a avaliação de websites de saúde relacionados às informações sobre o vírus HPV, bastante recorrente entre a população e no entanto pouco discutido, criando tabus que levam as pessoas a realizarem pesquisas isoladas na internet. Nos websites aqui avaliados, verificou-se que as informações apresentadas em geral são relevantes, com necessidade de atualização de conteúdo, considerando que a medicina é uma área que apresenta constantes evoluções em seus métodos de diagnóstico e tratamento, tornando importante a atenção à atualização dessas informações.

Para o critério de usabilidade, os websites pesquisados receberam boas avaliações, resultado compreendido pelo fato de aparecerem como os mais acessados na ferramenta de busca Google. Com base nos resultados encontrados, destaca-se o uso de termos próprios da área da medicina e que não podem ser compreendidos facilmente pelos leitores que não dispõem de tal conhecimento, o que leva a uma sugestão: que os websites passem a disponibilizar pequenos glossários.

Embora a limitação desta pesquisa esteja na quantidade de websites avaliados, cabe destacar que a ferramenta apresentada e a constatação de que é possível avaliar e ter um ranking de websites de saúde, de acordo com a sua qualidade, é benéfica para que, com base nas listas dispostas, os responsáveis por eles possam realizar adequações e ficar mais atentos para o conteúdo que disponibilizam. A 'concorrência entre websites' na internet tem muito a ganhar com a certificação de conteúdos e formas de apresentação destes.

Afinal, conforme alertou o médico Jorge Roque Cunha no artigo publicado pelo jornal Correio da Manhã (CM) de Portugal, "A quantidade não quer dizer qualidade. Como não existem sites de saúde validados em termos técnicos há muita desinformação" ${ }^{16}$. A internet pode ser considerada em muitos aspectos ainda como um ambiente desprovido de legislação específica e consequentemente sem fiscalização, e ainda com a facilidade de se ter um domínio de website e a disponibilidade de templates gratuitos que impulsionam o ‘faça você mesmo’ permitindo que qualquer pessoa, independentemente de seu nível de conhecimento em determinado assunto, possa ser uma propagadora de conteúdo.

A era digital, com aplicativos e buscas de conteúdo disponíveis na internet, é um caminho sem volta; desta forma, cabe a cada um estar atento e aprender a buscar e recuperar as fontes confiáveis em meio a tantas informações. Tem-se, então, como sugestão para estudos futuros que a quantidade seja estendida agregando também websites menos acessados, deixando disponível o resultado para usuários e também para aqueles que são administradores de tais websites.

\section{Referências}

1. $\quad$ Castells M. A sociedade em rede. São Paulo: Paz e Terra; 2011.

2. Barbosa $A$, coordenador. Pesquisa sobre o uso das tecnologias da informação e da comunicação no Brasil: TIC Domicílios e TIC Empresas 2009. São Paulo: Comitê Gestor da Internet no Brasil; 2010.

3. Mendonça APB, Pereira Neto A. Critérios de avaliação da qualidade da informação em sites de saúde: uma proposta. Reciis. 2015 jan.-mar. [citado em 2018 fev. 01];9(1):1-15. Disponível em: https://www. reciis.icict.fiocruz.br/index.php/reciis/article/view/930

4. Lopes ILAS. Proposta de critérios de qualidade para avaliação da informação em saúde recuperada nos sites brasileiros da world wide web [tese na internet]. Brasília, DF: Universidade de Brasília; 2006 [citado em 2018 fev. 01]. Disponível em: https://goo.gl/BGJgJ3

5. Silveira PCM,Costa AES, Lima CC. Cegueira na web: qualidade da informação. Rev. CEFAC. 2012 maiojun. [citado em 2018 fev. 01];14(3):430-7. http://dx.doi.org/10.1590/S1516-18462012005000025 
6. $\quad$ Mori S, Whitaker IY, Marin HF. Avaliação do website educacional em primeiros socorros. Rev. Esc Enferm USP. 2013 [citado em 2018 fev. 01];47(4):950-7. http://dx.doi.org/10.1590/S0080$\underline{623420130000400025}$

7. Nações Unidas. Transformando nosso mundo: a agenda 2030 para o desenvolvimento sustentável [internet]. Nova York; 2015 [citado em 2018 fev. 01]. Disponível em: https://goo.gl/c4aWgP

8. World Health Organization. Human papillomavirus (HPV) and cervical cancer. Genebra; 2016 [citado em 2018 fev. 01]. Disponível em: http://www.who.int/mediacentre/factsheets/fs380/en/

9. $\quad$ Creswell JW, Clark VLP. Pesquisa de métodos mistos. 2 ed. Porto Alegre: Penso; 2013.

10. Pereira Neto AF, Santos EM, Cruz MM, Torres RMC. Avaliação de sites de saúde em questão: a aids nos sites brasileiros de organizações não governamentais (ONG) de lésbicas, gays, bissexuais, travestis e transexuais (LGBT). Reciis. 2013 mar. [citado em 2018 fev. 01];7(1). Disponível em: http://www.brapci. ufpr.br/brapci/v/a/18868

11. International Organization for Standardization. Norma ISO 9241-11: requisitos ergonômicos para o trabalho com dispositivos de interação visual. Genebra; 2011. (Orientações sobre usabilidade; pt. 11).

12. Nielsen J, Loraner H. Usabilidade na web. Rio de Janeiro: Elsevier; 2007.

13. Stangherlin GF,Ghisleni TS, Dellazzana AL. Comunicação organizacional multimídia: um estudo de websites universitários [Internet]. In: Intercom Sul 2010: Anais do $11^{\circ}$ Congresso de Ciências da Comunicação na Região Sul; 2010 maio 17-19; Novo Hamburgo. São Paulo: Intercom; 2010 [citado em 2018 fev. 02]. Disponível em: https://goo.gl/96AHky

14. Cybis W. Ergonomia e usabilidade: conhecimentos, métodos e aplicações. 2 ed. São Paulo: Novatec; 2010.

15. Almeida Junior A. $90 \%$ dos brasileiros com internet buscam informações na rede sobre saúde. Correio Braziliense (Diários Associados). 2011 mar. 1. Disponível em: https://goo.gl/gMwP7r

16. Mania de pesquisar doenças na net já tem nome. Correio da manhã (Cofina Media). 2013 nov. 17. Disponível em: https://goo.gl/jNQGhn 